\title{
Borderline tuberculoid leprosy, lupus vulgaris and pulmonary tuberculosis: A rare association
}

\author{
Palzum Sherpa ${ }^{1}$, Amit Amatya ${ }^{2}$, Trishna Kakshapati ${ }^{1}$ \\ ${ }^{\prime}$ Department of Pathology, Patan Academy of Health Sciences, Lagankhel, Kathmandu, Nepal. \\ ${ }^{2}$ Department of Dermatology, Patan Academy of Health Sciences, Lagankhel, Kathmandu, Nepal.
}

\section{Keywords: \\ Leprosy; \\ Lupus vulgaris; \\ Tuberculosis;}

\begin{abstract}
Tuberculosis and leprosy are chronic mycobacterial infections that elicit granulomatous inflammation. The incidence of co-existence of pulmonary tuberculosis and leprosy has ranged from 2.5\%-13.4 percent. Cutaneous tuberculosis is a variant of extrapulmonary tuberculosis and its simultaneous occurrence with leprosy is uncommon. The concomitant presence of leprosy, pulmonary as well as cutaneous tuberculosis is rare.

We report a case of borderline tuberculoid leprosy, lupus vulgaris and pulmonary tuberculosis in a 45 years male who presented to the dermatology outpatient department with three morphologically distinct skin lesions over the posterior aspect of right leg. Ours is presumably the first case reported from Nepal, a country where both of these mycobacterial infections are endemic.
\end{abstract}

\section{Correspondence:}

Dr. Palzum Sherpa, MD

Assistant Professor, Department of Pathology,

Patan Academy of Health Sciences, Lalitpur, Nepal.

ORCHID ID: 0000-0001-7613-8485

E-mail: palzumsherpa@pahs.edu.np

Reveived : July 22 2018 ; Accepted : February 15 $5^{\text {th }} 2019$; Published : March $29^{\text {th }} 2019$

Citation: Sherpa P, Amatya A, Kakshapati T. Borderline tuberculoid leprosy, lupus vulgaris and pulmonary tuberculosis: A rare association. J Pathol Nep 2019;9:1505-7. DOI: 10.3126/jpn. v9i1.23382

Copyright: This is an open-access article distributed under the terms of the Creative Commons Attribution 4.0 International License, which permits unrestricted use, distribution, and reproduction in any medium, provided the original author and source are credited.

\section{INTRODUCTION}

Tuberculosis and leprosy are chronic mycobacterial infections that elicit granulomatous inflammation. Leprosy is caused by mycobacterium leprae and affects the skin and peripheral nerves. Tuberculosis is caused by mycobacterium tuberculosis and affects lung as well as extrapulmonary sites. Both these diseases are major global concerns: tuberculosis for its high prevalence and mortality and leprosy for its high rate of neuropathic disability. ${ }^{1}$ The annual new case detection rate in Nepal is 163 per 100000 for tuberculosis and 10.44 per 100000 for leprosy. The reported incidence of co-existence of pulmonary tuberculosis and leprosy has ranged from $2.5 \%-13.4 \%$ in endemic regions. ${ }^{2-4}$ Cutaneous tuberculosis is a variant of extrapulmonary tuberculosis and its simultaneous occurrence with leprosy is rare. ${ }^{5}$

We report a case of borderline tuberculoid leprosy, lupus vulgaris and pulmonary tuberculosis. Ours is presumably the first case reported from Nepal, a country where both of these mycobacterial infections are endemic. 


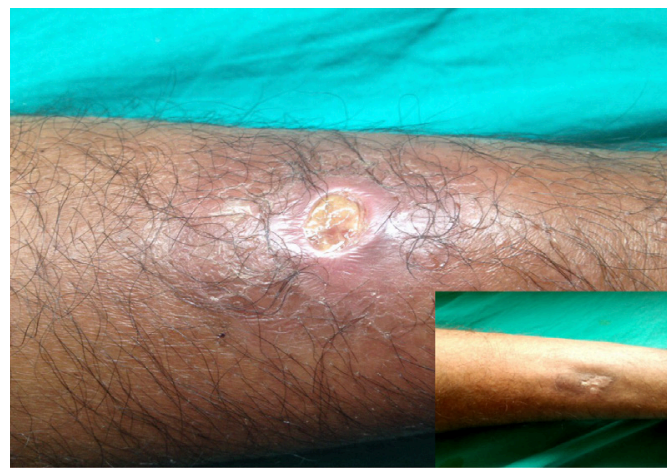

Figure 1: Second lesion which was ulcerated. Inset showing the healed lesion post anti-tubercular therapy.

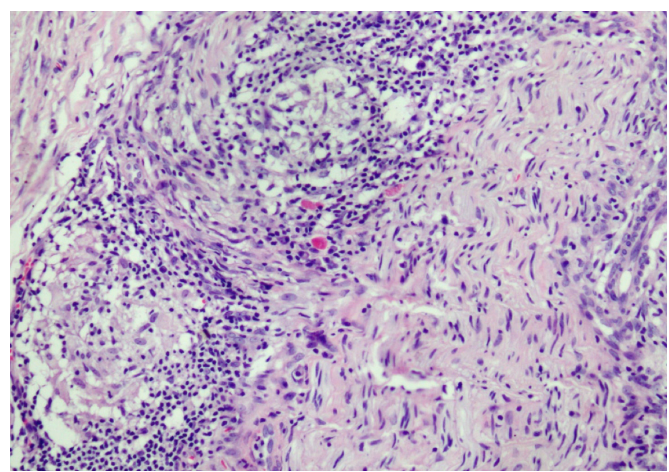

Figure 3: Perineural granulomas in borderline tuberculoid leprosy (HE stain; X400).

\section{CASE REPORT}

A 45 years male presented to dermatology outpatient department with three morphologically distinct skin lesions over the posterior aspect of right leg. The upper two lesions were present since 3 months and the lower one since 5 months. The lesions were roughly aligned. The first lesion was a $5 \times 4 \mathrm{~cm}$ visible lump situated $7 \mathrm{~cm}$ below the popliteal fossa. The overlying skin showed no erythema or hair loss. On palpation, it was firm, immobile, fluctuant and $4 \mathrm{ml}$ of thick, non-foul smelling pus was drained. The second lesion was an ulcer situated $8 \mathrm{~cm}$ above the lateral malleolus. It was $1 \mathrm{~cm}$ in diameter and circular with smooth border indented towards the yellowish ulcer base. It was slightly tender with no blood or pus discharge. The surrounding skin was mildly erythematous. During local anesthesia for punch biopsy in this area, anesthetic fluid spurted in various directions signifying sinuses within (fig. 1). The third lesion was a $6 \times 5 \mathrm{~cm}$ well defined, erythematous, annular plaque with scanty scales over the right ankle extending towards Achilles tendon. On examination, anesthesia to hot and cold sensation and hypoesthesia to pain, pressure and touch was observed. Feeder nerve was not palpable in the plaque. Right posterior tibial nerve was neither thickened nor tender.

There was no family history of pulmonary tuberculosis,

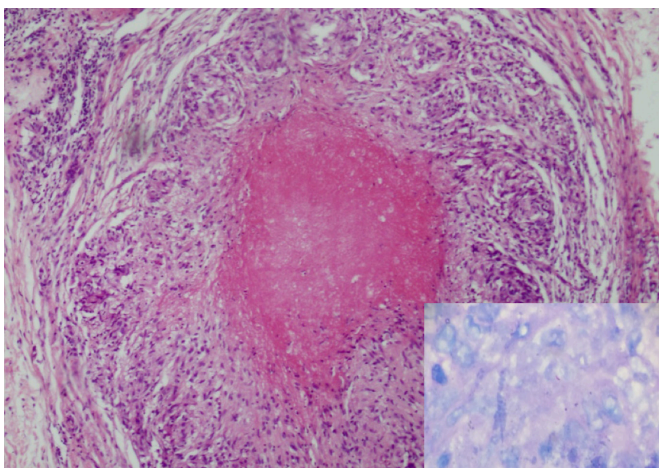

Figure 2: An epithelioid granuloma with central necrosis seen in lupus vulgaris (HE stain; X400). Inset showing acid fast bacilli in Ziehl Neelsen stain in lupus vulgaris (X1000).

cutaneous tuberculosis or leprosy. Slit skin smear test was negative. Chest x-ray showed a suspicious lesion and PCR of the sputum revealed mycobacterium tuberculosis of medium load which was not resistant to rifampicin. HIV serology was negative. All the other hematological and biochemical investigations were within normal limits.

Skin biopsies were obtained from the lower two lesions. Histopathology of the second lesion showed an inflammatory infiltrates composed of lymphocytes, plasma cells, neutrophils and histiocytes. Multiple epithelioid granulomas with central caseous necrosis and a few Langhan's type of multinucleated giant cells were present in the dermis as well as in the subcutaneous tissue. Ziehl Neelsen stain revealed acid fast bacilli (fig. 2). Skin biopsy specimen from third lesion showed thinned out epidermis with presence of pandermal lymphocytes and occasional plasma cells. The inflammatory infiltrates was extending into the skin appendages and around blood vessels. Epithelioid granulomas were present. A single nerve bundle was noted which was also infiltrated by the granulomas (fig. 3). Fite stain revealed no acid fast bacilli.

On the basis of clinical and histopathological findings two separate diagnoses were made simultaneously, lupus vulgaris on the second and borderline tuberculoid leprosy on the third lesion. The patient was referred to DOTS clinic and Category I treatment was started. Dapsone was planned to be added after a month to avoid drug interaction. However, the patient came for follow up after completion of antitubercular therapy six months later. The ulcerated lesion of lupus vulgaris was healed (fig. 2). However, the lesion of borderline tuberculoid leprosy was persistent and he was then started on antileprosy drug regimen.

\section{DISCUSSION}

Tuberculosis and leprosy are chronic granulomatous infections caused by mycobacterium tuberculosis and mycobacterium leprae respectively. The interaction between leprosy and tuberculosis and its consequence on 
the incidence of each other still remains a matter of debate. ${ }^{6}$ Chaussinad et al observed that the prevalence of leprosy was inversely related to that of tuberculosis and postulated the theory of antagonism between tuberculosis and leprosy. ${ }^{7}$ However, studies demonstrating the concomitant existence of tuberculosis and leprosy has been reported by Kumar et al, Gatner et al, Farhana et al and Rao et al. ${ }^{2,4-6}$ Co-infection is not infrequent and can occur in endemic areas like Nepal. Tuberculosis can occur throughout the spectrum of leprosy and the association is not infrequent when patients with leprosy are examined. ${ }^{4,5}$ The converse however, is not seen in patients with tuberculosis. In a study conducted by Gatner et al, $13.4 \%$ of the leprosy patients had pulmonary tuberculosis diagnosed on the basis of radiological and/ or bacteriological findings. This significant association seems likely to be due to higher prevalence of tuberculous infection and the immunologically compromised status of the leprosy patient. ${ }^{4}$ The risk of pulmonary tuberculosis is increased especially in patients of leprosy treated with glucocorticoids. ${ }^{8}$ In a study by Nigam et al, the gap interval between the development of leprosy and tuberculosis varied from 6 months to $10-15$ years. ${ }^{9}$ In our case the skin lesion of tuberculosis appeared 2 months before that of the leprosy which is uncommon. However, since the patient had no symptoms related to pulmonary tuberculosis and it was an incidental finding, its relation in terms of duration to the skin lesions could not be assessed. The co-existence of leprosy with pulmonary tuberculosis is more frequent than that with cutaneous tuberculosis. ${ }^{5,9}$ The concomitant presence of leprosy, pulmonary as well as cutaneous tuberculosis is uncommon and ours is presumably the first case reported from Nepal. In case of dual infections, antitubercular therapy with addition of antileprosy multidrug therapy for the type of leprosy is given. Rifampicin constitutes an important drug in the treatment regimen of both leprosy and tuberculosis. In patients of leprosy, tuberculosis must be ruled out if there is suspicion to avoid monotherapy of tuberculosis and prevent drug resistance to rifampicin. ${ }^{10}$

\section{CONCLUSION}

Despite limited reports, co-infection with leprosy and tuberculosis can occur. The possibility of dual infection should be considered when the clinical scenario is suggestive as early diagnosis is essential for optimal patient treatment.

\section{REFERENCES}

1. Scollard DM, Dacso MM, Abad-Venida ML. Tuberculosis and leprosy: classical granulomatous diseases in the twenty-first century. Dermatologic clinics 2015;33:541-62. Crossref

2. Kumar B, Kaur S, Kataria S, Roy SN. Concomitant occurrence of leprosy and tuberculosis- a clinical, bacteriological and radiological evaluation. Leprosy in India 1982;54:671-6. Crossref

3. Singh M, Kaur S, Kumar B, Kaur I, Sharma VK. The associated diseases with leprosy. Indian journal of leprosy 1987;59:315-21. $\underline{\text { Crossref }}$

4. Gatner EM, Glatthaar E, Imkamp FM, Kok SH. Association of tuberculosis and leprosy in South Africa. Leprosy review 1980;51:510. $\underline{\text { Crossref }}$

5. Ahmed Z. A case of lepromatous leprosy with co-existing tuberculosis verrucosa cutis. Leprosy review 2015;86:176-80. $\underline{\text { Crossref }}$

6. Rao GR, Sandhya S, Sridevi M, Amareswar A, Narayana BL. Lupus vulgaris and borderline tuberculoid leprosy: An interesting co-occurrence. Indian Journal of Dermatology, Venereology, and Leprology 2011;77:111. $\underline{\text { Crossref }}$

7. Chaussinand R. Apropos of the theory concerning the antagonism between tuberculosis and leprosy. La semaine des hopitaux: organe fonde par l'Association d'enseignement medical des hopitaux de Paris 1961;37:2304.

8. Sendrasoa FA, Ranaivo IM, Raharolahy O, Andrianarison M, Ramarozatovo LS, Rapelanoro Rabenja F. Pulmonary tuberculosis and lepromatous leprosy coinfection. Case reports in dermatological medicine $2015 ; 2015$.

9. Nigam P, Dubey AL, Dayal SG, Goyal BM, Saxena HN, Samuel KC. The association of leprosy and pulmonary tuberculosis. Leprosy in India 1979;51:65-73. Crossref

10. Verma AK, Singh A, Prakash V, Bhatia A, Kant S. Coexistence of leprosy and pulmonary tuberculosis: An uncommon entity. Medical Journal of Dr. DY Patil University 2015;8:675. Crossref

\section{Conflict of Interest: None}

